O tratamento psicoterápico é estudado em profundidade pelo Pe. Dr. Manoel do Carmo e pela Dra. Ruth Christina Fernandes. A abordagem científica e o relato de casos verídicos buscam um aprimoramento da Consciência Moral como abertura total, num sentido de personalização, conhecimento e valorização de si e, ao mesmo tempo, de abertura ao transcendente que leva à vivência do Amor oblativo de Deus.

Pe. Gilberto Kasper, coloca o leitor em contato com o trabalho de Rubem César Fernandes, do ISER. A análise do Pe. Gilberto permite uma aproximação crítica da Mariologia, quanto a alguns títulos de Nossa Senhora Aparecida: Nossa Rainha, Senhora e Mãe e, com sabor de sincretismo, Oxum e Iemanjá.

O Magistério do Papa Paulo VI sobre a Natureza do Direito Eclesial é analisado pelo Pe. Dr. João Carlos Orsi. O autor realça três períodos do pensamento do Papa: o primeiro período (1965-1969) fala da inseparabilidade entre a Igreja Jurídica e a Igreja da Caridade. O segundo período (1970-1972) destaca a Justiça na Igreja, e o terceiro período discute a Eclesiologia de Comunhão e as demais questões de ordem antropológica que devem permear o Direito Canônico.

A Revista se encerra com o trabalho da Professora Jeni Bertoni Nimtz que, formada em Literatura e Teologia, apresenta um estudo sobre o Barroco Brasileiro de Gregório de Matos destacando, nas poesias desse autor, a controvérsia secular entre o Teocentrismo, cuja teologia está assinalada pela consideração de que Deus é o centro do Universo e a medida de todas as coisas, e o Antropocentrismo, que lança diretrizes teológicas no sentido de se compreender a criatura humana como sujeito de sua prórpia história. A pesquisa contempla a influência da Literatura Sacra Jesuítica dos séculos XVI a XVII.

A Diretoria da Pontificia Faculdade de Teologia Nossa Senhora da Assunção, seus professores, alunos e funcionários desejam um Santo Natal e um Ano Novo de Paz a todos os assinantes e leitores de sua Revista de Cultura Teológica.

Com as melhores bençãos de Deus Conselho de Redação

\section{A DINÂMICA ESCATOLÓGICA DO ESPÍRITO SANTO}

\section{Prof. Dr. Renold Johann Blank}

\section{1 - REDESCOBRIR O AGIR ESCATOLÓGICO DO ESPÍRITO SANTO}

Falar em Escatologia do agir do Espírito Santo não é costume. Do Espírito Santo falamos quando se trata de Pentecostes, quando descrevemos o agir dele na Igreja, ou ainda, quando no decorrer da atual onda pentecostal, cristãos e cristãs se sentem movidos por dinâmicas religiosas extáticas, nas quais querem reconhecer o agir do Espírito que batiza e faz falar em línguas.

Para os cristãos comuns, nem essa experiência do Espírito é real, e desde que, por ocasião de seu crisma, ouviram que agora teriam recebido o Espírito Santo, a sua compreensão deste fenômeno se restringe à concepção de uma pomba, com a qual, para eles, este tal Espírito Santo toca a margem do ridículo, no mínimo do negligenciável e, com isso, desaparece de seu mundo religioso. Ou, do outro lado, se torna uma noção tão abstrata e espiritualizada, que nada mais tem a ver com a sua vida concreta e real e menos ainda com as questões de morte e de uma última finalidade deste mundo. Assuntos que em todo caso, as pessoas preferem deixar para mais tarde.

O símbolo da pomba não ajudou na descoberta daquela dinâmica, da qual os Textos Sagrados dizem que ela era presente como energia e princípio atuante desde o começo do cosmo. Ela agiu na inimaginável tempestade cósmica termonuclear, através da qual se formou o universo: O Big-Bang, a grande explosão inicial. Início de uma história evolutiva, cujo fim nem podemos imaginar. História dinâmica e chocante do início do mundo, e desde o início, dizem os textos, adejava sobre as águas o sopro de Deus. Um sopro impetuoso, quando acreditamos nas declarações dos especialistas em cosmologia. Eles situam as temperaturas daquele início do mundo em bilhões de graus, $\mathrm{e}$ a velocidade da expansão do cosmo em centenas de milhares de quilômetros por segundo. Não parece ser lugar adequado para uma pomba. Mas, era o lugar do agir do Espírito de Deus. Um espírito que também chamamos de Espírito de amor. Denominação que já melhor se aproxima do simbolismo tradicional da pomba, pelo menos a partir do momento, onde sabemos que nos 
tempos antigos do Oriente Médio, Ischtar, a grande deusa do amor da Babilônia' sempre foi representada com pombas, que eram as aves especificamente ligadas a ela.

O Espírito Santo e as aves de uma deusa do amor. Chocante, mas não tão fora do contexto quando nós nos lembramos que Teilhard de Chardin já tinha sugerido, que a energia evolutiva do cosmo deveria ser vista como energia de amor. Energia de convergência, que faz unir os elementos dispersos, imputando em dimensões cósmicas um movimento evolutivo que culminará naquilo que chamamos o Ponto Ômega do cosmo. Tal Ponto Ômega, porém, se apresenta como convergência final de tudo aquilo que nós chamamos "o ser". Nesta sua convergência final, o cosmo inteiro chegará ao seu fim último, alcançará a sua meta final, a sua plenificação que se realiza em Deus. A última finalidade do mundo e do cosmo, obra de uma energia dinâmica dẹ amor que chamamos Espírito Santo, é a plenificação desde cosmo em Deus! E a energia que impulsiona esta plenificação, se chama "Espírito de Deus", Espírito Santo, Terceira pessoa da Trindade. De repente, este espírito não mais fica longe de todo e qualquer pensamento escatológico, mas no centro dele, no seu coração, indispensável e impetuosamente necessário para toda reflexão no campo da escatologia.

Este fato se toma mais concreto e teologicamente relevante, quando interligamos as realidades cosmológicas também com aquela outra dinâmica que costumamos denominar a dinâmica histórica do Reino de Deus. Dinâmica profundamente escatológica, porque ela aponta para a realização daquilo, que é o plano salvífico de Deus. Ela aponta para a plenificação do Reino, que ao mesmo tempo é a plenificação da história do mundo e do cosmo. A dinâmica desta plenificação é convergente, transformadora e histórica. Três características, nas quais se interligam as verdades escatológicas com as características básicas daquilo que chamamos Espírito Santo. Esta interligação se manifesta no nível histórico deste mundo da mesma maneira como no nível do indivíduo e de sua história individual de salvação.

${ }^{1}$ Cf. Othmar KEHL, Die Welt der altorientalischen Bildsymbolik und das Alte Testament, Zürich: ed. Benziger, 1980, p. 126.

8 REVISTADE
2 - O ESPírito SANTO ESTÁ PRESENTE NA DINÂMUCA ESCATOLÓGICA DE CONVERGÊNCIA DO MUNDO, RUMO À REALIZAÇÃO DE SUA META FINAL

O Espírito Santo, assim o diz a dogmática, é o fogo de amor que corre entre Deus Pai e Deus Filho. E este amor é Deus, à mesma maneira como o Pai e o Filho; possuidor de todas as infinitas qualidades daquilo que é a natureza de Deus unindo o Pai e o Filho num mar dinâmico de amor, onde o Pai sabe do amor do Filho e o Filho sabe do amor do Pai, e este amor é pessoa que por sua vez sabe que é amor e que como amor é a força dinâmica de convergência entre as três pessoas da trindade, a força que une a dinâmica do amor. De um amor que o Pai de tal maneira faz arder desde dentro de seu Filho que dele regressa com o mesmo ardor de volta ao Pai. Este amor que une as duas pessoas divinas é por sua vez pessoa, sabendo de si-mesma, consciente que é o amor que une Pai e Filho, e amando por sua vez o Pai e o Filho é a terceira pessoa da Trindade - o Espírito Santo no qual o círculo do amor desta Trindade se fecha.

O espírito de amor é a energia que une a Trindade no seu ser, e é este espírito que pela vontade desta Trindade está agindo também no cosmo. Os primeiros textos do Gênesis afirmam que ele estava agindo na dinâmica inimaginável daquilo que a cosmologia hoje chama o Big-Bang; a grande explosão inicial, pela qual o cosmo começou ${ }^{2}$.

É este mesmo Espírito que enche o mundo durante todos os bilhões e bilhões de anos, no decorrer dos quais este mundo evolui. Nós o vemos de fora, e nos constatamos naquela evolução uma constante convergência de partículas, rumo à formação de estruturas cada vez mais complexas. Teilhard de Chardin descreveu este movimento de complexificação, e era ele, que na sua concepção/da evolução cósmica, chamou de "amor" a energia que deve estar agindo atrás de todo o processo cósmico da evolução ${ }^{3}$. Para Teilhard, "a energia básica do cosmo é o amor. Este amor, porém, pode ter a sua origem só naquele amor que é Deus. O princípio motor de toda evolução do cosmo é Deus; e este Deus é amor." É a forma mais alta e o princípio totalizante do processo de convergência, pelo qual está marcado o processo cosmológico

${ }^{2}$ Cf. Gn 1,2

${ }^{3}$ Teilhărd de CHARDIN, Das Göttliche Mileu, Olten/Freiburg: Walter, 1969, p. 175-180. 
da evolução. Este princípio é Deus, é uma pessoa transcendente, e é ela que se encontra na origem e no fim de uma evolução, cujo significado mais profundo é este: Tornar consciente de que no coração da evolução está Deus"*4.

A energia do amor - a energia divina - o Espírito de Deus. É este Espírito que Deus Pai transmitiu aos homens (cf. Gn 2,7). É este mesmo Espírito que Deus Filho sopra do alto da cruz por dentro deste mundo ${ }^{5}$. É este Espírito, cuja vinda e presença sacramental celebramos na festa de Pentecostes. $O$ Espírito divino. O Espírito de Deus que enche o mundo. Este espírito é amor. A profunda dinâmica e a força irresistível do amor divino.

Sabemos que todo amor une aquilo que está dividido. Todo amor incentiva um processo dinâmico de convergência daquilo que está separado. O Espírito de Deus é amor em pessoa. E sendo amor, também ele age da mesma maneira. Ele age dentro do processo histórico, para que este processo se torne um processo de união. Um processo, no decorrer do qual, as partes separadas se unem, as divergências serão superadas e os conflitos cederão lugar à harmonia. É este o projeto final e cósmico de Deus. Um mundo unido entre si e unido com Deus. Uma humanidade que superou o ódio e a discórdia, um Reino da Paz, da justiça e do amor. Todo o processo histórico do mundo e do cosmo se revela a partir destes parâmetros como uma única dinâmica processual, ruma para esses valores. E no coração desta dinâmica, encontramos como motor e princípio ativo o Deus amor, chamado Espírito Santo. Em todo lugar e em toda situação onde homens e mulheres estão agindo, para que a história inteira se torne um processo, rumo à realização destes valores escatológicos, o Espírito Santo está ativo. Ele está presente como motor e incentivador, assim como Jesus o formulou na sua parábola do fermento (Lc 13,20 ss). O objetivo final e escatológico deste seu agir, é a convergência de toda a humanidade e de todo o cosmo em Deus. Aquilo que Teilhard chamou

${ }^{4}$ Cit. cf. G. MAGLOIRE/H.CUYPERS, Leben und Denken Pierre Teilhard de Chardin, Frankfurt: ed. Ulistein, 1967, p. 129

${ }^{3}$ Cf. Jo 19, 30: "... inclinando a cabeça, entregou o espirito". A palavra "entregar o espírito" tem um duplo sentido. De um lado significa expiar; do outro lado, porém, significa também em sentido literal aquilo que diz: Entregar o seu espírito, isto é, o Espírito de Deus, o Espírito Santo, que é o espirito de união entre as pessoas da Trindade. Este espírito, o Deus Filho, Jesus, entrega ao mundo. A Bíblia de Jerusalém fala, neste contexto, do "prelúdio da efusão do Espírito" (cf. também: Jo 1,33; 20,22).

10 REVISTADE CULTURATEOLÓGICA o Ponto Ômega, união do cosmo inteiro com Deus, plenificação e fim de toda escatologia. E no centro dela, encontramos como energia e dinâmica de convergência o Espírito de Deus, a terceira pessoa da Trindade, o Espírito Santo.

Este Espírito Santo, porém, não age sozinho. O seu objetivo de um mundo convergente não se realiza de maneira quase automática, mágica e independente de nós. $O$ Espírito Santo age à maneira como Deus sempre agiu e está agindo dentro deste mundo: ATRAVÉS DE HOMENS E MULHERES! Deus sempre agiu através de nós na história. Este fato vale também para o agir da terceira pessoa da Trindade. Ali, onde homens e mulheres trabalham, para que o grande processo escatológico de um mundo convergente se realize, ali encontramos o Espírito Santo. É ele a profunda dinâmica do amor que incentiva como motor o processo de convergência do mundo, rumo aos valores escatológicos de um mundo unido entre si e unido com Deus.

Tal processo de convergência, no entanto, por sua vez é divergente e conflitivo. Ele exige conversão. E de novo encontramos o Espírito Santo como força motora e incentivadora atrás do processo histórico de uma conversão progressiva do mundo.

O Espirito Santo é amor. Amor sempre é uma energia de união e de cunvergência. Este Espirito de amor que é Deus está presente no processo histórico da evolução do cosmo, desde o inicio deste cosmo. Por causa disso, toda história do cosmo é a história escatológica de convergência, ruma a uma última e definitiva união de todos os homens entre si e com Deus. O motor deste processo é o Espírito Santo que é amor. Deus, no entanto, nunca age sozinho. Por causa disso, os instrumentos, pelos quais o Espírito Santo realiza o objetivo escatológico na história, são os homens e as mulheres que agem dentro desta história. Um tal agir implica, necessariamente, num processo dialético e conflitivo de conversão.

\section{3) O ESPírito SANTo ESTÁ PRESENTE NA DinÂMICA ESCATOLÓGICA DE CONVERSÃo E TRANSFORMAÇão DESTE MUNDO}

O Deus Espírito enche o mundo desde que este mundo existe. Este Deus, porém, é um Deus da vida, um espírito da vida, e o lema dele, a partir do primeiro momento da existência do cosmo até a sua plenificação escatológica, é sempre o mesmo: MAIS VIDA! 
Eis os parâmetros de seu agir: Como Espírito da vida, ele incentiva para que situações de menos vida sejam transformadas em situações de mais vida.

Da mesma maneira como Jesus (a Segunda Pessoa da Trindade), definiu o seu agir com o objetivo de mais vida ${ }^{6}$, o agir do Espírito Santo, por sua vez, só pode ser compreendido a partir do mesmo paradigma: MAIS VIDA! E, sendo assim, é que este cosmo, desde o primeiro momento da criação, está cheio do Espírito Santo; não é de admirar; pois que também a tendência primordial de toda a evolução é esta: Mais vida.

Todo o processo da evolução do cosmo se revela como sendo um processo rumo a mais vida. Começando com a convergência de partículas subatômicas, passando pela formação das primeiras estruturas vivas e chegando àquilo que hoje constatamos como manifestação de vida, podemos ver sempre a mesma tendência: $A$ vida se intensifica e se amplia.

O que nós podemos observar deste processo de expansão da vida é o seu lado exterior, o fenômeno em si. O que não é possível observar pelos nossos instrumentos científicos é o lado interior do processo, o agir do Espírito da vida por dentro da matéria, depois por dentro dos seres vivos, e finalmente no homem.

No mundo inteiro, porém, o Deus Espírito está ativo da mesma maneira como Deus estava agindo na ocasião da passagem do povo pelo Mar Vermelho: Os historiadores egípcios da época não enxergavam a sua presença, assim como hoje, também, os nossos observadores científicos não conseguem detectar o agir da energia do espírito de Deus, dentro do processo da expansão da vida. Ele, porém, está presente. Está agindo conforme os parâmetros dele: MAIS VIDA!

O objetivo deste espírito de vida, no entanto, não se esgota no processo de fazer aparecer e desenvolver a vida. $O$ objetivo dele é um objetivo escatológico, e este objetivo tem como última finalidade a vida em plenitude. Para esta vida em plenitude, usamos na teologia a sigla de "Salvação". O objetivo final do agir do Espírito Santo é a vida em plenitude do mundo inteiro e de todos os seus seres conforme a capacidade e a característica deles $^{7}$. Para que se atinja este objetivo, Deus, mais uma vez, não optou pelo

6f. Jo 10,10: "Eu vim para que tenham a vida e a tenham em abundância",

${ }^{7}$ Cf. Catecismo da Igreja Católica, $n^{\circ}$. 1046-1048; cf. Jo 3,17.

12 REVISTA DE

CULTURA TEOLÓGICA caminho opressivo do poder mas, bem pelo contrário, escolheu os caminhos lentos e tortuosos da conversão, que passa pelos corações e pelas estruturas humanas. A imagem deste processo, escolhido e usado pelo próprio Jesus, é aquela de uma massa que, sob o agir do fermento, se transforma (Lc 13,20).

Este fermento está agindo de maneira constante por dentro da massa até que toda a massa se tenha transformado. Não há imagem melhor para descrever o agir escatológico do Espírito Santo dentro da história. É ele o fermento que transforma. É ele a força que incentiva para a conversão. O rumo desta conversão, porém, é bem clara. É uma conversão em direção de mais vida.

O Espírito Santo se revela, assim, como sendo a grande energia transformadora dentro do mundo. É ele que incentiva e impulsiona o processo de uma evolução escatológica no decorrer da qual se realizará aquilo que é o objetivo final de toda a obra criadora e salvífica de Deus: A VIDA EM PLENITUDE.

Esta vida em plenitude, porém, não se alcança por um processo mágico. Úma vez ultrapassado o nível da matéria não-consciente, a caminhada rumo a mais vida tem a superar cada vez mais estruturas conscientes que se opõem à vida. Estruturas que impedem a vida; estruturas opostas a vida que se manifestam de muitas maneiras, como egoísmo, como interesse pessoal, como poder, como mentira, como exploração. Todas estas estruturas, sejam elas pessoais ou sociais, se põem em oposição àquela energia transformadora, que quer a ampliação dos espaços de vida em todos os níveis. - Porque tal ampliação dos espaços de vida significaria abandonar o egoísmo, abandonar a mentira e abandonar a exploração de outros. Nisso, porém, os defensores de estruturas de morte não têm interesse. Por causa disso, eles se opõem à ampliação das estruturas de vida, e com isso, eles se opõem ao agir do Espírito Santo dentro do mundo.

Também aqui vale o princípio, conforme o qual este Espírito sempre agiu: Ele passa através do agir humano e não realiza os seus objetivos através de atos mágicos. Ele os realiza através do agir de homens e mulheres que se deixam incentivar a serem os instrumentos da vida. Ele os realiza dentro de uma profunda dinâmica de vida que sopra onde quer.

REVISTADE CULTURA TEOLÓGICA 
O Espírito incentiva para o AGIR:

- A sua imagem é o vento que sopra. Sua força impulsiona o processo histórico-escatológico numa direção específica:

- Rumo a mais vida

- Rumo a mais amor

- Este processo fica marcado por uma dialética constante.

- Esta dialética marca também a história da Igreja (cf. Mt 8, 24).

\section{4 - O AGIR TRANSFORMADOR SE TORNA O CRITÉRIO DE DISCERNIMENTO PARA DETECTAR O VERDADEIRO ESPÍRITO SANTO}

O Espírito de Deus sopra onde quer. Esta imprevisibilidade fez tremer os guardiões da ordem de todas as épocas e de todas as instituições. Esta imprevisibilidade de um Espírito de vida derramado sobre todos os viventes (J1 3), se torna incômodo muitas vezes também aos guardiões da grande disciplina dentro destas instituições. Por causa disso, tentaram domesticar este Espírito e canalizá-lo em regras e códigos sacrossantos e aprovados para todos os tempos. Mas, um Espírito derramado sobre todos os viventes, de tal maneira que "os filhos e filhas de vocês se tornarão profetas;... os velhos terão sonhos e os jovens terão visões" (Jl 3,1), um tal espírito questiona as classes hierarquizadas dentro de todas as instituições. Ele questiona a rejeição da mulher, porque também as filhas se tornarão profetas. Ele questiona as barreiras que se construíram no decorrer dos séculos entre incluídos e excluídos, entre homens e mulheres, entre ortodoxos e heterodoxos, entre ricos e pobres.

Um Espírito derramado até "sobre os escravos e escravas" (J1 3,2), derruba todas as barreiras de classes e privilégios sociais e também todas as ideologias, sejam elas políticas, sociais ou religiosas, com as quais se tenta justificar uma tal estratificação.

Um Espírito do qual "os velhos terão sonhos e os jovens terão visões" (J1 3,1 ) evoca uma sociedade e uma Igreja, na qual não haverá mais barreiras de línguas e de castas e de iniciados ou não-iniciados. Em vez disso, haverá a superação das barreiras, e aqueles que falavam línguas diferentes, no sentido real ou figurativo, se encontram todos juntos numa nova comunidade de irmãos e irmãs. É esta a grandiosa imagem escatológica, transmitida por At 2,1-13. Nela não se exprime aquilo que hoje, no âmbito do pentecostalismo se compreende pelo termo "falar em línguas"; mas muito mais a realização daquilo que é um dos objetivos escatológicos do Espírito de Deus: $A$ superação das separações e a eliminação das divisões entre os homens.

De um tal Espírito muitas vezes não se fala, quando se fala hoje do Espírito Santo. Em vez disso, se fez dele em muitos casos uma caricatura que provoca efeitos de transe. Em vez disso, o chocante sinal de uma superação das fronteiras e dos distintivos degenerou num balbuciar sem sentido que, por sua vez, ergue novas barreiras. Degenerou em shows religiosos, onde milhares de pessoas assistem em estado mais ou menos extático a um espetáculo espiritual da mesma maneira, como algumas semanas antes, tinham assistida a shows de uma cantora; da mesma maneira, como no mês seguinte, assistirão a um jogo de futebol.

Falamos hoje muito do Espírito Santo, e em muitos casos se fez deste Espírito transformador, um incentivador para um show-business religioso. Todas aquelas forças, que em nada se interessam pelo agir verdadeiro de um Espírito que transforma e que perturba, estão aplaudindo.

É, frente a uma tal conjuntura, que devemos mais uma vez lembrar que o neoliberalismo atual, para compensar as profundas frustrações produzidas por seu sistema, propõe hoje de maneira sistemática três níveis de compensação para estas frustrações por ele mesmo causadas: O primeiro é o consumo; o segundo é o sexo; o terceiro é a religião.

A religião, aprovada pelo sistema neoliberal deve ser centrada, todavia, no indivíduo, e os seus efeitos - pelo amor de Deus - não podem ir além de provocar conforto ou êxtase espiritual. De um Espírito que transforma todas as coisas, o neoliberalismo nem quer ouvir falar. Ele até faz tudo para apagar o mais rápido possível uma tão "subversiva ameaça".

Tantos cristãos e tantas cristãs, porém, se deixam seduzir e, sem perceber, entram no jogo de um sistema que com bons olhos vê os cristãos como assistentes de mega-shows espirituais, mas que de jeito algum está interessado em seguidores de um Espírito que renova todas as coisas. De um Espírito, cuja ação renovadora questiona todas as estruturas injustas, todos os sistemas que oprimem, todas as instituições que excluem.

Muitas vezes, nem os próprios cristãos percebem que jogam o jogo do sistema. Deslumbrados pelo esplendor de um novo triunfalismo, eles esquecem que o Espírito do Senhor que renova a face da terra, em nada se orienta pelos critérios numéricos de uma sociedade de consumo, mas muito mais e em primeiro lugar, incentiva para uma Igreja, onde os primeiros são os últimos, onde os poderosos lavam os pés dos seus irmãos mais pequeninos, e 
onde o dinheiro, gasto nos mega-shows, seria aplicado numa verdadeira evangelização conscientizadora. Numa evangelização que incentiva para a transformação deste mundo a partir dos critérios do verdadeiro Espírito de Deus. Critérios que, como todo mundo sabe e já esqueceu, se orientam em valores como pobreza e serviço, amor e fraternidade, e onde não se exclui ninguém.

Ali; onde estes valores não estão em primeiro lugar, o Espírito de Deus não está! E, assim, podemos constatar que em muitos casos se repete a mesma tragédia histórica que produziu a rejeição de Jesus: Uma instituição, chamada o Templo, rejeitava em nome de Deus a mensagem da Segunda Pessoa da Trindade.

O perigo é tão grande que até cristãos de hoje estão seguindo os mesmos trilhos sem o perceber porque, da mesma maneira como na época de Jesus, também hoje é possível deturpar a verdadeira mensagem da Terceira Pessoa da Trindade. As obras do verdadeiro Espírito são as obras do Reino de Deus. E estas obras se qualificam por uma clara tendência transformadora. O Espírito Santo não é o guardião de uma situação estabelecida. O Espírito Santo transforma, e a sua transformação incomoda da mesma maneira, como o fogo incomoda (cf. At 2,3). E os homens e mulheres que se deixaram incendiar por aquele fogo, incomodam também, dentro e fora da Igreja. Porque é através deles e delas que o Espírito está agindo neste mundo, transformando o rumo desta história em direção à realização do grande projeto escatológico, que é a plenificação do Reino de Deus.

Esta plenificação escatológica, no entanto, passa por um processo histórico de Conversão. Conversão do mundo e conversão da Igreja. O critério desta conversão, encontramos nas obras daqueles que se dizem seguidores do Espírito Santo. Enquanto estas obras produzem uma verdadeira transformação rumo a um mundo onde há menos injustiça, menos egoísmo, menos conflitos e menos mentiras, elas são obras do verdadeiro Espírito Santo. Obras, através das quais, este Espírito está transformando o mundo, rumo ao projeto escatológico de uma realização plena do Reino.

Enquanto estas obras, porém, só sustentam o bem-estar espiritual dos fiéis ou os desejos de poder de algumas lideranças, elas apagam o Espírito e sustentam o outro espírito de um sistema, interessado em sufocar a força transformadora do Espírito Santo nos prazeres de um delírio de consumo e de consolações religiosas (cf. 1Ts 5, 19). "Discernir os Espíritos" se torna assim de novo a grande tarefa de todo cristão.

Ali, onde em nome do Espírito, homens e mulheres transformam estruturas de injustiça em situações de justiça; estruturas de exclusão em situações de amor; estruturas de poder em estruturas de serviço; ali, o verdadeiro Espírito Santo de Deus está agindo, transformando o mundo e conduzindo esta história rumo à realização do projeto escatológico de Deus. Em todo lugar, porém, onde em nome do Espírito se quer manter situações opostas ao Reino de Deus; onde em nome do Espírito se quer voltar a um individualismo religioso, fechando os olhos diante dos desafios de um engajamento histórico e social conforme o exemplo de Jesus, ali se venera um Espírito falso que não é o Espírito de Jesus, o verdadeiro Espírito Santo, em cujo nome se renovam todas as coisas.

\section{O ESPIRITO SANTO É UM ESPIRITO DE VIDA.}

Jesus entregou este espírito na sua morte ao mundo (Jo 19,30).

$O$ Espirito de vida é transformador, o seu lema é este: MAIS VIDA e MENOS SITUAÇÕES DE MORTE. Por causa disso, o Espírito de Deus produz ACONVERSÃO DO MUNDO.

Conversão não significa em primeiro lugar um ato espiritual, mas A TRANSFORMAÇÃO DE TODAS AS SITUAÇÕES DE MORTE, EM SITUAÇÕES DE VIDA.

O ESPÍRITO SANTO É UMA DINÂMICA TRANSFORMADORA DENTRO DA HISTÓRIA

Ele incentiva o processo de transformação do mundo, rumo à plenificação do projeto escatológico de Deus: O REINO DE DEUS. Reino de Deus, porém significa:

A TRANSFORMAÇÃO DESTE MUNDO NUM MUNDO DE

- MAIS JUSTIÇA

- MAIS AMOR

- MAIS PAZ

- MAIS FRATERNIDADE

- MAIS VERDADE

Renold Johann Blank é doutor em Filosofia e Teologia e professor titular na Pontifícia Faculdade de Teologia Nossa Senhora da Assunção 